\title{
廃グリセリンの熱分解による合成ガス製造
}

\section{Syngas Production from Waste Glycerol through Thermal Decomposition}

\section{河崎 澄}

公立大学法人滋賀県立大学工学部 機械システム工学科

厂 522-8533

滋賀県彦根市八坂町 2500

Kiyoshi KAWASAKI

The University of Shiga Prefecture, School of Engineering

Hassaka-cho 2500, Hikone, Shiga, 522-8533, Japan
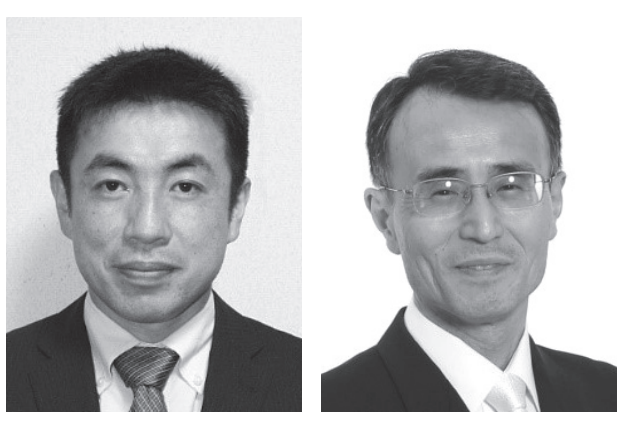

山根 浩二

公立大学法人滋賀県立大学工学部

機械システム工学科

† $522-8533$

滋賀県彦根市八坂町 2500

Koji YAMANE

The University of Shiga Prefecture,

School of Engineering

Hassaka-cho 2500, Hikone, Shiga,

522-8533, Japan

論文要旨:バイオディーゼル燃料 (FAME) 製造過程の副生物であるグリセリンを熱分解することにより, 合成ガスを製造する研究を行った。ガス化に及ぼす反応条件の影響を,グリセリン試薬を用いた熱分解実験, および化学平衡計算により調査した。実験の結果, 反応温度 $800 \mathrm{~K}$ 以上において, グリセリンは $\mathrm{H}_{2}, \mathrm{CO}$, および $\mathrm{C} 1$ C 2 炭化水素からなる可燃性ガスに分解されることを示した。さらに, 水添加を行うことにより, 主に $1000 \mathrm{~K}$ 以下の温度条件におけるガス化率が向上することや，FAME 製造過程において得られた廃グリ セリンも，グリセリン試薬と同様に熱分解できることなどを示した。

\begin{abstract}
The aim of this study is to clarify the appropriate reaction condition for the thermal decomposition of glycerol to a syngas in order to utilize wasted glycerol derived from biodiesel production. The effect of reaction temperature on gaseous products were examined by the experiment and the chemical equilibrium simulation. The experimental results show that a glycerol is decomposed to $\mathrm{H}_{2}$, CO, and $\mathrm{C} 1-\mathrm{C} 2$ hydrocarbons under the reaction temperature beyond $800 \mathrm{~K}$. In addition, the effects of water addition on decomposition temperature is also investigated. The results show that the water addition is effective to improve the gasification efficiency with relatively low reaction temperature below $1000 \mathrm{~K}$. Furthermore, it is found that the composition of gaseous product obtained from an actual wasted glycerol is similar to that from a reagent glycerol.
\end{abstract}

Key words: bio fuel, glycerol, FAME, gasification, alternative energy

\section{1 まえがき}

植物油をエステル交換反応することにより，ディーゼ ル機関用の脂肪酸メチルエステル燃料（Fatty acid methyl ester; FAME, 通称 バイオディーゼル燃料) を製造すると, 副生物としてグリセリン（廃グリセリン） が生じる。FAMEに対するグリセリンの生成量は，質 量比で約 10\%, エネルギー比で約 4.7\%である（Fig. 1)。 グリセリンは食品添加物や医薬品, 化粧品の原料となる 有用な化学物質である。しかし, 一般的な FAME 製造 工程では, エステル交換反応の触媒として水酸化カリウ ム $\mathrm{KOH}$ などのアルカリ触媒が用いられる。そのため, 廃グリセリンはアルカリ金属を含有しており，そのまま

\begin{tabular}{|c|c|c|c|c|c|}
\hline & 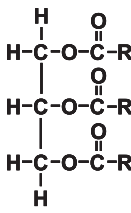 & $+3 \mathrm{CH}_{3} \mathrm{OH}$ & $\mathrm{NaOH}, \mathrm{KOH}$ & $\begin{array}{c}\mathrm{O} \\
\mathrm{CH}_{3}-\mathrm{O}-\mathrm{C}-\mathrm{R}_{1} \\
\mathrm{O} \\
\mathrm{CH}_{3}-\mathrm{O}-\mathrm{C}-\mathrm{R}_{2}+ \\
\mathrm{O} \\
\mathrm{CH}_{3}-\mathrm{O}-\mathrm{C}-\mathrm{R}_{3}\end{array}$ & 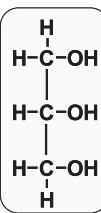 \\
\hline & Triglyceride & $\mathrm{MeOH}$ & & FAME & Glycerol \\
\hline Mass & $1 \mathrm{~kg}$ & $0.1 \mathrm{~kg}$ & & $1 \mathrm{~kg}$ & $0.1 \mathrm{~kg}$ \\
\hline Energy & $37 \mathrm{MJ}$ & $2 \mathrm{MJ}$ & & $38 \mathrm{MJ}$ & $1.8 \mathrm{MJ}$ \\
\hline
\end{tabular}

Fig. 1 Theoretical mass and energy balance in FAME production from vegetable oil.

では化学原料として利用することができない。このよう な背景から, 廃グリセリンを他の有用な化学物質に変換 して用いる方法が検討されている。

例えばJaecker-Voirolらは, 廃グリセリンからアセ タールやエーテルを合成して，ディーゼル燃料に混合し

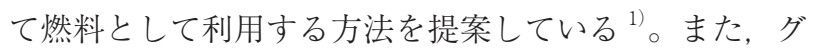




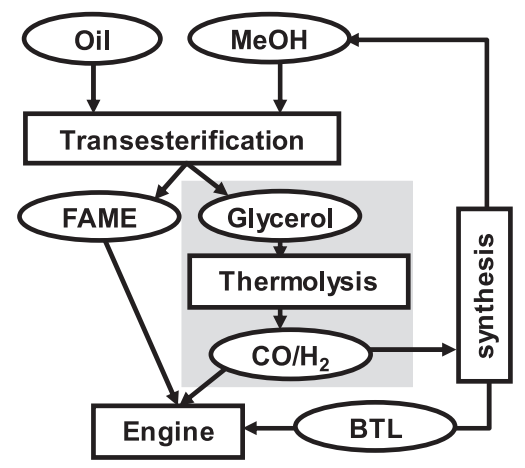

Fig. 2 Utilization of waste glycerol through a synthesis gas.

リセリンから $\mathrm{H}_{2}$ や $\mathrm{H}_{2}-\mathrm{CO}$ 混合ガス（合成ガス）を製造 する方法も検討されている。Fig. 2 に示すように, 合成 ガスは, ガスエンジンや燃料電池の燃料として直接利用 することができるほか，F-T 合成を経由すれば軽油・ガ ソリンと同等の液体燃料（Biomass to Liquid;BTL）や, FAME の原料であるメタノールを製造することができ る。

グリセリンからの合成ガス製造に関しては，水溶液相 下での改質法 ${ }^{2-4)}$ や，水蒸気改質法 ${ }^{5,6)}$ が検討されてい る。一方, 著者らはグリセリンを熱分解することにより， 合成ガスを得る方法の検討を行ってきた。本報では，グ リセリンの熱分解反応に打ける反応温度, 水添加量の変 化がガス組成抢よび熱・物質収支に及ぼす影響を，ガス

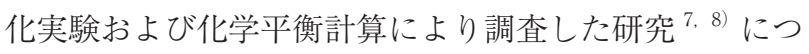
いて解説する。

\section{2 実験および計算方法}

\section{$2 \cdot 1$ 熱分解装置}

Fig. 3 は, グリセリンの熱分解実験に用いた装置の概 略を示す。グリセリンは，動粘度を下げるために $65^{\circ} \mathrm{C}$ に予熱されたのち，定量注入ポンプにより連続的に圧送 され，キャピラリーステンレスパイプを通り，チューブ 型電気炉で加熱された石英炉心管 (内径 $46 \mathrm{~mm}$, 長さ $750 \mathrm{~mm}$ ）の内部に供給される。炉から流出したガスは 水槽で泠却したのち, サンプルバックに捕集し, ガスク

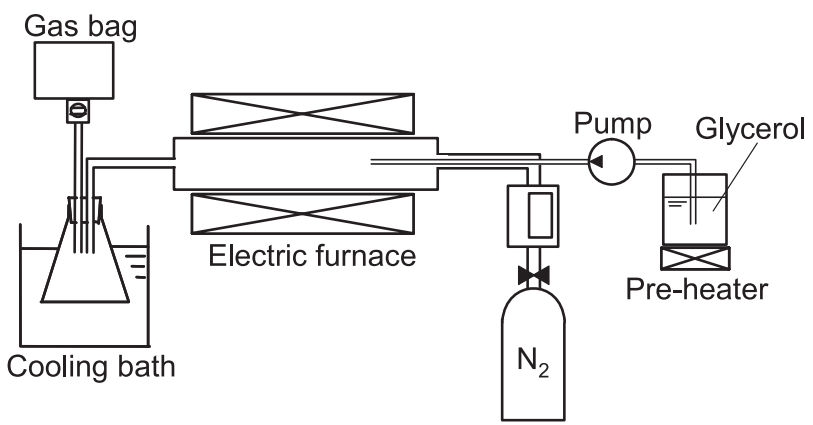

Fig. 3 Experimental apparatus.
ロマトグラフにより組成を分析した。熱分解により発生 するガスの希䣋およびパージには窒素を用いた。グリセ リンの供給量は $0.88 \mathrm{~g} / \mathrm{min}$, 窒素の流量は $1.0 \mathrm{~L} / \mathrm{min}$ と した。すなわち,グリセリンと窒素のモル比は $1: 4.7$, 空間速度は $58 \mathrm{~h}^{-1}$ である。

\section{$2 \cdot 2$ 評価指標の計算方法}

ガスクロマトグラフにより求めた熱分解ガスの組成 と, グリセリンおよび窒素の流量から, ガス成分 $i$ の単 位時間あたりの流出量 $\dot{n}_{i}(\mathrm{~mol} / \mathrm{min})$ を計算し， $\dot{n}_{i}$ を基 にしてガス化率 $\eta_{\mathrm{G}}$ および発熱量増加割合 $\eta_{\mathrm{H}}$ を以下の ように計算した。

$\eta_{\mathrm{G}}$ は，単位時間あたりに炉に流入するグリセリン中 の炭素原子数と, 熱分解ガス中の炭素原子数の比と定義 し, 以下の式に従って求めた。

$$
\eta_{\mathrm{G}}=\frac{\dot{n}_{\mathrm{CO}}+\dot{n}_{\mathrm{CO} 2}+\dot{n}_{\mathrm{CH} 4}+2 \dot{n}_{\mathrm{C} 2 \mathrm{H} 4}+2 \dot{n}_{\mathrm{C} 2 \mathrm{H} 4}}{3 \dot{n}_{\mathrm{C} 3 \mathrm{H} 803}}
$$

さらに, $\eta_{\mathrm{H}}$ はグリセリンの発熱量に対する熱分解ガ スの発熱量の比と定義し, 以下の式に従って算出した。 ここで, $H_{1, i}$ はガス成分 $i$ の低位発熱量である。

$$
\eta_{\mathrm{H}}=\frac{\sum \dot{n}_{\mathrm{CO}} H_{1, \mathrm{i}}}{\dot{n}_{\mathrm{C} 3 \mathrm{H} 803} H_{\mathrm{l}, \text { Сзно0з }}}
$$

\section{$2 \cdot 3$ 化学平衡組成の計算方法}

グリセリンの熱分解ガス組成に及ぼす反応温度，およ び氷蒸気添加の影響を化学平衡計算により予測した。計 算にはフリーソフト GASEQ Ver0.799) を用い，グリセ

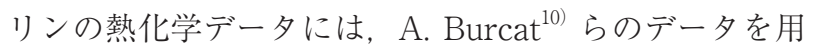
いた。

\section{3 結果および考察}

\section{$3 \cdot 1$ 反応温度の影響}

Fig. 3 に示した装置を用い, 800〜 $1200 \mathrm{~K}$ の反応温度 で，市販のグリセリン試薬（純度 99.0\%）の熱分解を行 い，物質および熱の収支を解析した。Fig. 4 はグリセリ

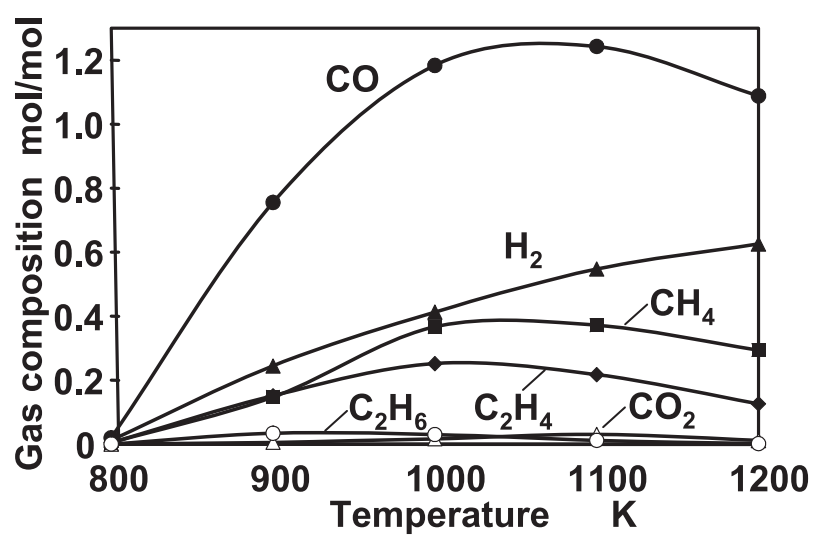

Fig. 4 Variation in gas composition with reaction temperature (experimental results). 
ン $1 \mathrm{~mol}$ あたりの各種ガス成分の発生量を示す。Fig. 4 より,グリセリンを熱分解して合成ガスを得るためには, $800 \mathrm{~K}$ 以上の温度が必要であることがわかる。発生する ガスの組成に着目すると, 最も発生量の多いガスは CO であり，次いで $\mathrm{H}_{2}, \mathrm{CH}_{4}$ がほぼ同量ずつ発生する。 $\mathrm{C} 2$ 以上の炭化水素についてみると, $\mathrm{C}_{2} \mathrm{H}_{4}$ は $\mathrm{CH}_{4}$ の半分程 度発生するが, $\mathrm{C}_{2} \mathrm{H}_{6}$ はほとんど発生しない。C3 の炭化 水素の発生量は温度によらず検出限界以下であった。 $\mathrm{CH}_{4}, \quad \mathrm{C}_{2} \mathrm{H}_{4}$ の発生量は $1000 \mathrm{~K}$ までは増加するが，それ 以上の温度では分解が進み減少する。このとき, $\mathrm{H}_{2}$ は 増加するが，COはかえって減少する結果となった。こ の CO の減少は, 温度の上昇による熱分解の促進効果よ りも，炉内での熱膨張すなわち体積流量増加にともなう 反応時間の短縮の影響の方が強く現れた結果と推察され る。

Fig. 5 は, 化学平衡計算により求めた熱分解ガスの平 衡組成と温度の関係を示す。Fig. 5 によると, 反応温度 を約 $1100 \mathrm{~K}$ 以上に高めれば固形炭素 C（solid）の析出 がほぼ 0 となり， $\mathrm{CO}$ と $\mathrm{H}_{2}$ 以外の成分はほとんど生成 されないことがわかる。実験結果とは異なり COよりも $\mathrm{H}_{2}$ 発生量の方が多いのは, 実験では $\mathrm{CH}_{4}, \mathrm{C}_{2} \mathrm{H}_{4}$ が分解 されずに流出するのに対して，平衡計算ではこれらはほ ほ 0 となるためである。

Fig. 6 およびFig. 7 はそれぞれ，反応温度に対するガ ス化率 $\eta_{\mathrm{G}}$, および発熱量増加割合 $\eta_{\mathrm{H}}$ の変化であり, 実 験值と平衡計算による結果を比較して示す。Fig. 6, Fig. 7 によると， $\eta_{\mathrm{G}}$ および $\eta_{\mathrm{H}}$ の実験值はいずれも $1000 \mathrm{~K}$ で最大となり, それ以上の温度では $\mathrm{CO}$ 発生量が減少し た影響で $\eta_{\mathrm{G}}, \eta_{\mathrm{H}}$ ともに減少する。一方，平衡計算の結 果によると $\eta_{\mathrm{G}}, \eta_{\mathrm{H}}$ はいずれも温度に対して単調増加し, $1100 \mathrm{~K}$ 以上において $\eta_{\mathrm{H}}>1$ となる。また, 約 $1200 \mathrm{~K}$ 以 上の条件では $\mathrm{H}_{2}$ と $\mathrm{CO}$ のみが発生し, このとき得られ る $\eta_{\mathrm{H}}$ の最大值は約 1.15 となる。以上の結果より, 装置

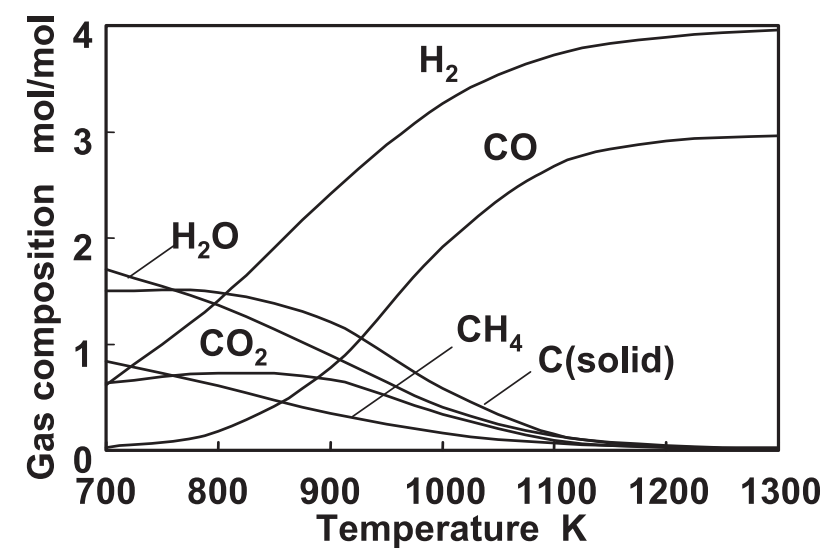

Fig. 5 Variation in gas composition with reaction temperature (simulated results).

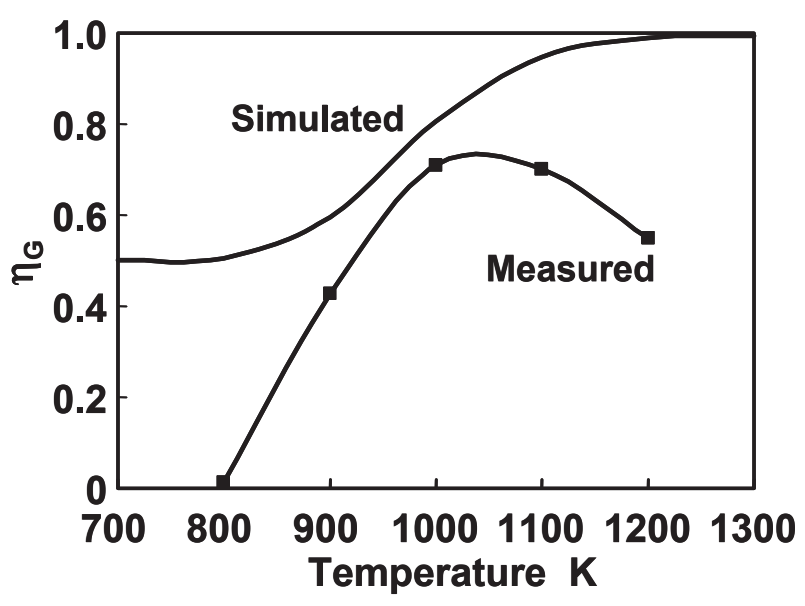

Fig. 6 Measured and simulated gas conversion efficiency.

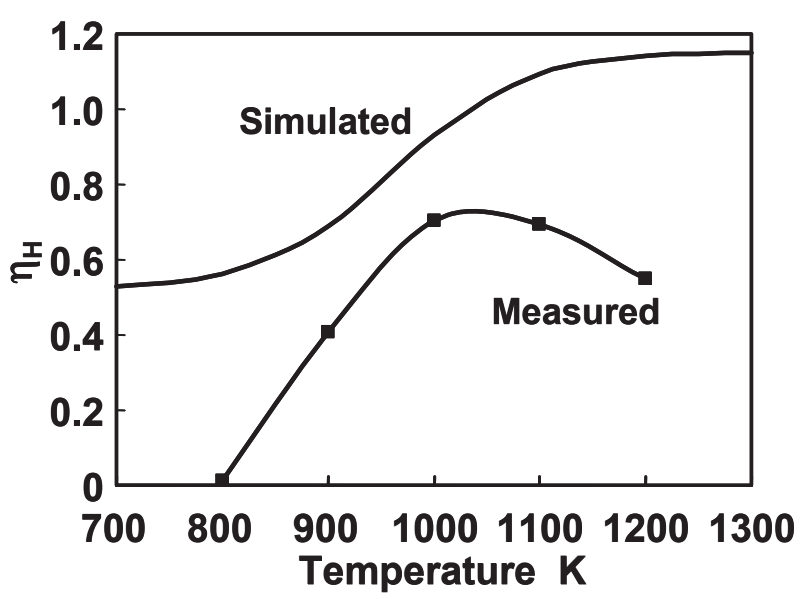

Fig. 7 Measured and simulated heat value ratio.

および反応条件の改善によりガス化率を高めることがで きれば，ガス化のための投入熱量を生成物の反応熱とし て回収できる可能性が示唆される。なお, $1000 \mathrm{~K} よ り$ も低温側において，実測のガス化率が計算值よりも低い のは, 実験では化学平衡に達するだけの十分な反応時間 が確保されていないためと考えられる。

\section{$3 \cdot 2$ 水添加の影響}

つぎに, 水添加によるガス化率向上の可能性を, 化学 平衡計算により調べた。Fig. 8 は, 反応温度 $1000 \mathrm{~K}$ に おける，グリセリン $1 \mathrm{~mol}$ あたりの水添加量（mol/ mol）に対する平衡組成の変化を示す。水添加量 0 $1 \mathrm{~mol} / \mathrm{mol}$ の範囲では, 水蒸気改質反応（3）によって 炭素 $\mathrm{C}$ の割合が減少して, $\mathrm{CO}$ および $\mathrm{H}_{2}$ が増加する。

$$
\mathrm{C}+\mathrm{H}_{2} \mathrm{O}=\mathrm{CO}+\mathrm{H}_{2}
$$

水添加量を $1 \mathrm{~mol} / \mathrm{mol}$ よりも大きくすると, CO およ び $\mathrm{CH}_{4}$ の割合が減少して, $\mathrm{H}_{2}$ と $\mathrm{CO}_{2}$ の割合が増加する。 $\mathrm{CO}$ の減少はシフト反応 (4), $\mathrm{CH}_{4}$ の減少はメタンの改 質反応（5）によるものである。 


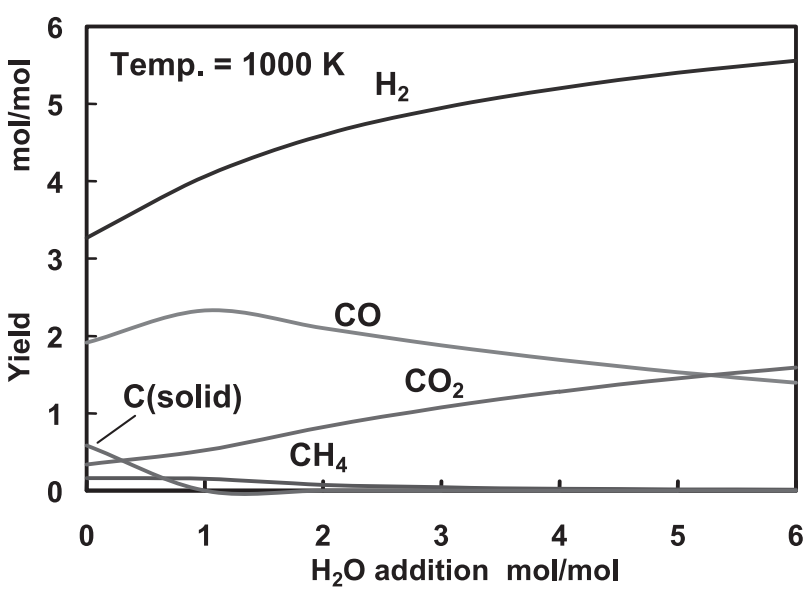

Fig. 8 Variation in yield with mole ratio of added water (simulated results).

$\mathrm{CO}+\mathrm{H}_{2} \mathrm{O}=\mathrm{CO}_{2}+\mathrm{H}_{2}$

$\mathrm{CH}_{4}+\mathrm{H}_{2} \mathrm{O}=\mathrm{CO}+3 \mathrm{H}_{2}$

Fig. 9, Fig. 10 はそれぞれ，水添加量 $x(\mathrm{~mol} / \mathrm{mol})$ を 0〜 $4 \mathrm{~mol} / \mathrm{mol}$ の間で変化させた場合の $\eta_{\mathrm{G}}$ および $\eta_{\mathrm{H}}$ と 温度の関係を示す。Fig. 8 で示したように， $x$ を $1 \mathrm{~mol} /$ mol よりも大きくすれば，固形炭素の析出が抑制され る。そのため, 水添加を行うことにより, 主に $1000 \mathrm{~K}$ 以下の低温条件における $\eta_{\mathrm{G}}$ が向上する。その結果, Fig. 10 に示すように， $x=0$ の条件では $\eta_{\mathrm{H}}$ は約 $1200 \mathrm{~K}$ で最 大值（約 1.15）に達するのに対して， $x=4$ とすれば, $\eta_{\mathrm{H}}$ は約 $1000 \mathrm{~K}$ で最大值に達することがわかる。

平衡計算の結果より，グリセリンの熱分解に水添加を 行うことによって，ガス化率を維持したまま分解に必要 な温度を低減できる可能性が示された。そこで次に，グ リセリンの熱分解に及ぼす水添加の影響を実験によって 調査した。実験では,グリセリンに対する水の添加量を, モル比 0〜 $4 \mathrm{~mol} / \mathrm{mol}$ の間で変化させた。水添加グリセ

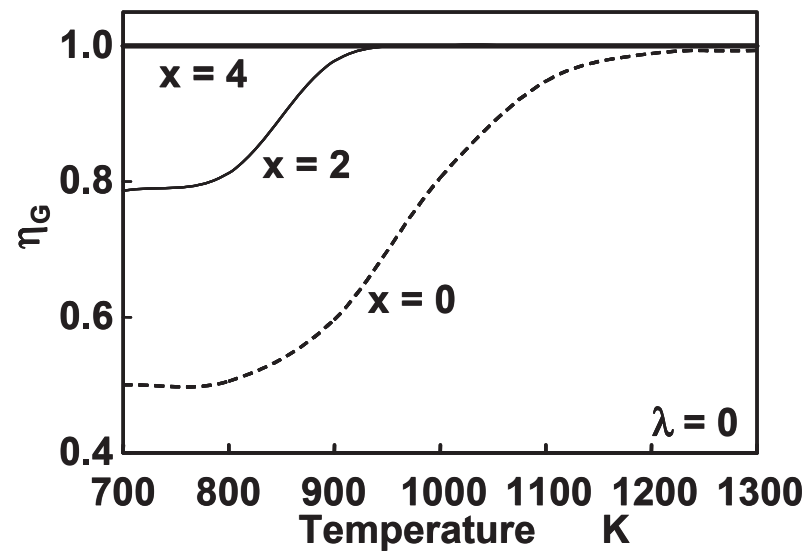

Fig. 9 The effect of $\mathrm{H}_{2} \mathrm{O}$ addition on $\eta_{\mathrm{G}}$.

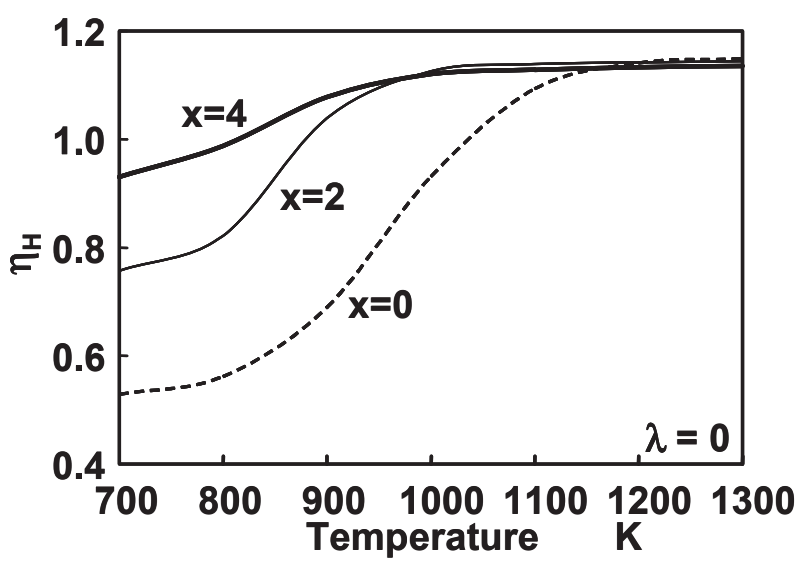

Fig. 10 The effect of $\mathrm{H}_{2} \mathrm{O}$ addition on $\eta_{\mathrm{H}}$.

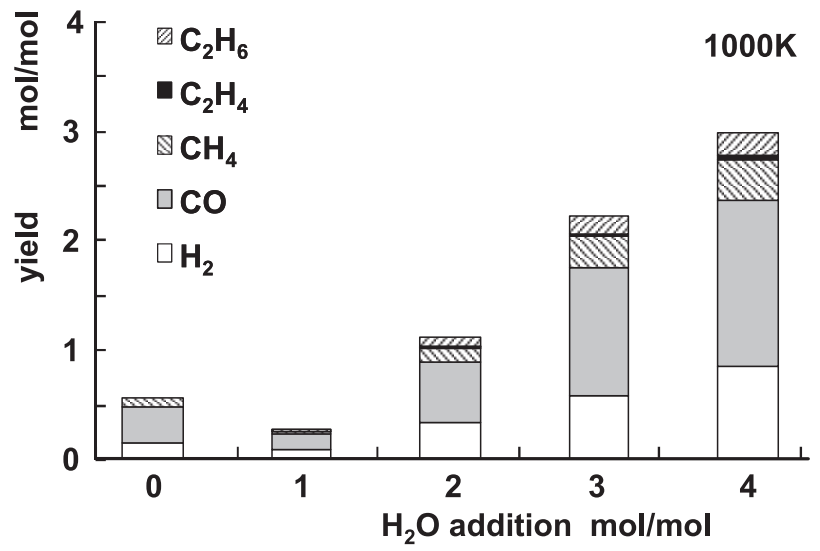

Fig. 11 Yield of gaseous products upon varying $\mathrm{H}_{2} \mathrm{O}$ addition.

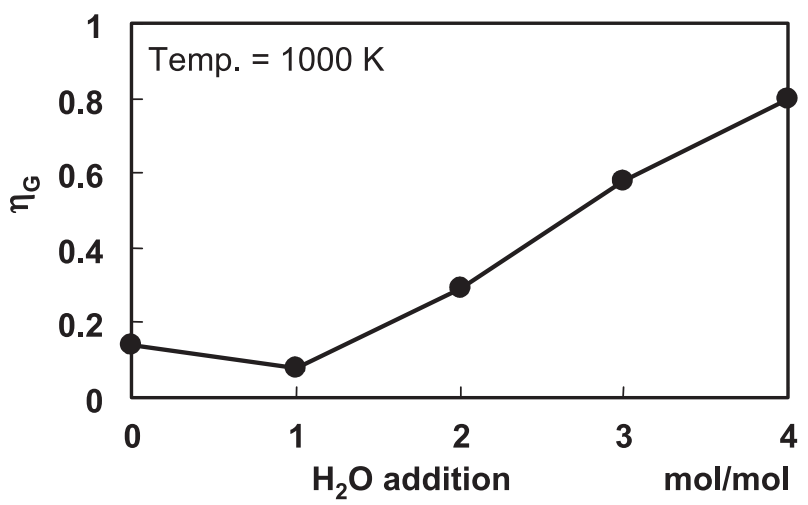

Fig. 12 Variation in gas conversion efficiency.

リンの反応管への供給量は $4.6 \pm 0.3 \mathrm{mmol} / \mathrm{min}$ とし, 空 間速度を一定とした。

Fig. 11 は, 反応温度 $1000 \mathrm{~K}$ のもとでの, 種々の水添 加量に拈ける各生成物量を示す。Fig. 11 より, 水添加 量が $1 \mathrm{~mol} / \mathrm{mol}$ を超えると, $\mathrm{CO}$ および $\mathrm{H}_{2}$ の生成量が, 水を添加しない場合よりも大きくなる。その結果, Fig. 12 に示すように, ガス化率 $\eta_{\mathrm{G}}$ は水添加によって向上し, 添加量 $4 \mathrm{~mol} / \mathrm{mol}$ において $\eta_{\mathrm{G}}=0.8$ となった。 
ここで，実験では $\mathrm{CO}_{2}$ 生成量は検出限界以下であっ たのに対して, Fig. 8 に示した平衡計算では, $\mathrm{CO}_{2}$ 生成 量は約 $1 \mathrm{~mol} / \mathrm{mol}$ であった。この違いが生じた理由とし て, 添加した水は式 (4) に示す CO のシフト反応よりも, 式（3）に示す熱分解反応に主に関与したことが考えら れる。

\section{$3 \cdot 3$ 廃グリセリンの熱分解}

最後に，アルカリ触媒法による FAME 製造過程にお いて得られたグリセリン（廃グリセリン）の熱分解実験 を行った。FAMEの原料は食用大豆油とし, エステル 交換反応の触媒には水酸化カリウム $\mathrm{KOH}$ を用いた。熱 分解を行う前に，廃グリセリン中に含まれるメタノール を減圧蒸留により分離した。このメタノールは, エステ ル交換反応に与えた過剰分のメタノールである。

Fig. 13 に，廃グリセリンを熱分解した場合の生成物 を，グリセリン試薬の場合と比較して示す。反応温度は $1000 \mathrm{~K}$ および $1200 \mathrm{~K}$ ，水添加量は $4 \mathrm{~mol} / \mathrm{mol}$ とした。

Fig. 13 より, 廃グリセリンもグリセリン試薬と同様に 熱分解することが可能であり， $\mathrm{H}_{2}, \mathrm{CO}, \mathrm{CH}_{4}$ および $\mathrm{C} 2$ 炭化水素が生成することがわかる。ただし，廃グリセリ ンからのガス生成量は, グリセリン試薬を原料とした場 合に比べて低い結果となった。

Fig. 13 において, 各成分の発生量の差に着目すると, グリセリン試薬に対する廃グリセリンからの $\mathrm{H}_{2}$ 生成量 の減少分に比べて, CO および $\mathrm{HC}$ 生成量の減少分が大 きい。また，廃グリセリンの方が $\mathrm{CO}_{2}$ 生成量が大きい。 このように，廃グリセリンを原料とした場合に，生成物 に占める $\mathrm{H}_{2}$ および $\mathrm{CO}_{2}$ の割合が大きくなった原因とし ては，式（4）に示したシフト反応が優先的に進んだこ とが考えられる。

なお，廃グリセリンを熱分解した場合には，Fig. 14 に示すように黒鉛状の物質がグリセリン供給管の出口,

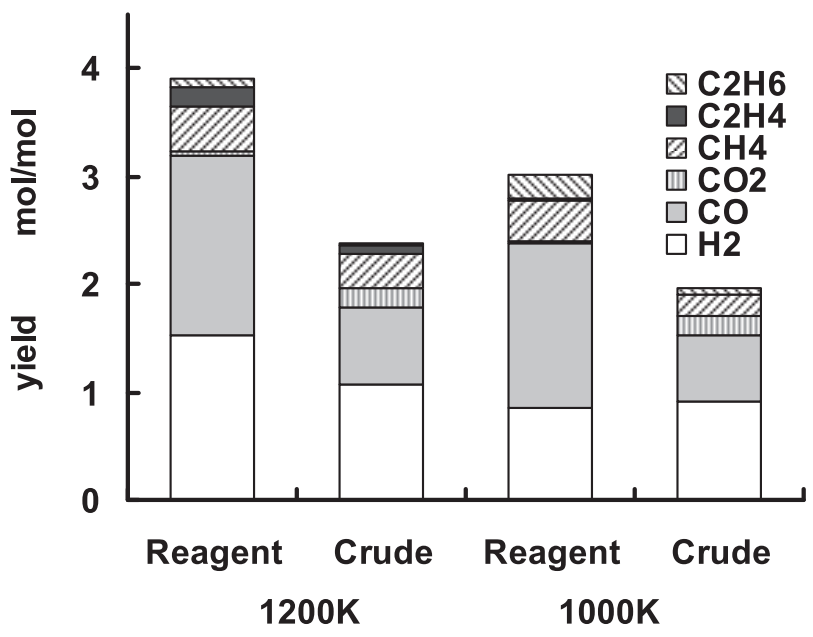

Fig. 13 Yields from crude and reagent glycerol.

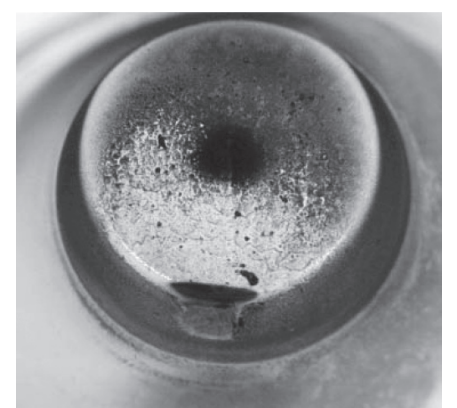

Fig. 14 Carbonaceous deposit on the inner surface of a reactor tube.

およびガラス製反応管の内壁に析出した。これらの析出 物は，エステル交換反応の中間生成物である，モノグリ セリド，ジグリセリド，未反応油脂（トリグリセリド） が廃グリセリンに含まれていたことに起因すると考えら れる。これらの不純物は $500^{\circ} \mathrm{C}$ 以上の高温下では容易に

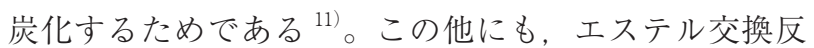
応の触媒として加えたカリウムが廃グリセリンに残留 し，それが熱分解過程において粒子となり，炭素凝集の 核となった可能性も考えられる。

\section{4 まとめ}

以上，FAME 製造過程において得られた廃グリセリ ンを熱分解することにより，合成ガスを製造する研究に ついて解説した。ガス化に及ぼす反応条件の影響を，グ リセリン試薬を用いた熱分解実験, および化学平衡計算 により調査した。実験の結果, 反応温度 $800 \mathrm{~K}$ 以上にお いて, グリセリンは $\mathrm{H}_{2}, \mathrm{CO}$, および $\mathrm{C} 1 \sim \mathrm{C} 2$ 炭化水素 からなる可然性ガスに分解されることを示した。また， 化学平衡計算により，発熱量増加割合は最大で 1.15 ま で改善できる可能性があることを示した。さらに，水添 加を行うことにより，主に $1000 \mathrm{~K}$ 以下の温度条件にお けるガス化率が向上することや，FAME 製造過程にお いて得られた廃グリセリンも，グリセリン試薬と同様に 熱分解できることなどを示した。

本研究の一部は, 平成 21 年度 グリセリン新規用途開 発研究助成制度（日本石検洗剂工業会）の補助を受けて 実施した。

\section{文 献}

1) A. Jaecker-Voirol, I. Durand, G. Hilion, B. Delfort, and X. Montagne. Oil \& Gas Science and Technology, 63, 395 (2008).

2) R. D. Cortright, R. R. Davda and J. A. Dumesic. Nature, 418, 964 (2002)

3) N. Luo, X. Fu, F. Cao, T. Xiao and P. P. Edwards. Fuel, 87, 3483 (2008) 
4) N. Luo, X. Zhao, F. Cao, T. Xiao and D. Fang. Energy Fuels, 21, 3505 (2007)

5) T. Hirai, N. Ikenaga, T. Miyake and T. Suzuki. Energy Fuels, 19, 1761 (2005).

6) S. Adhikari, S. Fernando and A. Haryanto. Energy Fuels, 21, 2306 (2007).

7）河崎澄, 山根浩二, 森慶太, 日本機械学会論文集 B 編, 75, 490 (2009).

8) K. Kawasaki and K. Yamane. Proc. of the International
Conference on Power Engineering-09 (ICOPE-09), 3-49 (2009).

9) http://www.gaseq.co.uk

10) A. Burcat and B. McBride. Technion Israel Institute of Technology, Aerospace Engineering Report, TAE 804, (1997), ftp://ftp.technion.ac.il/pub/supported/aetdd/ Thermodynamic

11）森慶太, 森田銀, 河崎澄, 山根浩二, 自動車技術会 2009 秋季学術講演会前刷集，No.132-09，11（2009）. 